\title{
Prolonged nucleic acid conversion and false-negative RT-PCR results in Indonesian patients with COVID-19: A case series
}

\author{
Ika Trisnawati \\ UGM \\ Riat Al Khair \\ UGM \\ Aditya Rifqi Fauzi \\ UGM \\ Gunadi ( $\square$ drgunadi@ugm.ac.id) \\ UGM https://orcid.org/0000-0002-4707-6526
}

\section{Case Report}

Keywords: COVID-19, case series, false negative of RT-PCR, prolonged nucleic acid conversion, SARS-Cov-2

Posted Date: July 15th, 2020

DOl: https://doi.org/10.21203/rs.3.rs-39961/v1

License: (c) (i) This work is licensed under a Creative Commons Attribution 4.0 International License. Read Full License

Version of Record: A version of this preprint was published at Annals of Medicine and Surgery on November 1st, 2020. See the published version at https://doi.org/10.1016/j.amsu.2020.09.040. 


\section{Abstract}

Background: Prolonged nucleic acid conversion and false-negative results of real-time reverse transcription polymerase chain reaction (RT-PCR) might occur in some patients with COVID-19 rather than recurrence of infection. Here, we reported four cases of COVID-19 with prolonged nucleic acid conversion and falsenegative results of RT-PCR in our institution.

Case presentation: Case 1: A 36-year-old-male patient complained of coughing up phlegm one week before admission. His chest X-rays showed mild pneumonia in the right lung. His swab test was confirmed positive for SARS-Cov-2. Besides the last two consecutive negative results, he also had negative results of RT-PCR twice (the $6^{\text {th }}$ and $8^{\text {th }}$ tests) from a total of 11 swab tests. Case 2: A 54-year-old-male patient complained of shortness of breath that worsened with activity. He had a comorbidity of diabetes. His chest X-rays showed inhomogeneous opacity on bilateral paracardial and lateral aspects. His swab test was confirmed positive for SARS-Cov-2. Besides the last two consecutive negative results, he also had negative results of RT-PCR once (the $5^{\text {th }}$ test) from a total of 8 swab tests. Case 3: A 47-year-old man presented with complaints of fever, cough, sore throat, and diarrhea. He had comorbidities of asthma and heart rhythm disorders. His chest X-rays showed bilateral pneumonia. His swab test was confirmed positive for SARS-Cov-2. Besides the last two consecutive negative results, he also showed negative results of RT-PCR twice (the $4^{\text {th }}$ and $6^{\text {th }}$ tests) from a total of 11 swab tests. Case 4 : A 56 -year-oldfemale complained of lethargy and diarrhea. She has a history of hyperthyroidism. His chest X-rays showed bilateral pneumonia. She was confirmed positive for SARS-Cov-2. Besides the last two consecutive negative results, she also had negative results of RT-PCR twice (the $2^{\text {nd }}$ and $10^{\text {th }}$ tests) from a total of 14 swab tests.

Conclusions: Our cases further confirmed the occurrence of prolonged nucleic acid conversion and the possibility of false negative results of RT-PCR in patients with COVID-19 instead of recurrence of infection. These findings might have an implication on the management of patients with COVID-19 who have already clinically and radiologically recovered, particularly related to subsequent spreading of the infection in the community.

\section{Introduction}

In December 2019, an outbreak of infection of severe acute respiratory syndrome-coronavirus-2 (SARS-CoV-2) was detected in Wuhan, China. This virus has the etiology of Coronavirus disease 2019 (COVID-19), first announced by the World Health Organization (WHO) on January 12, 2020 [1,2]. COVID-19 was officially announced to be a pandemic on March 11, 2020, and until now, it has spread to 213 countries and territories, with a total of cases as of June 12, 2020 , of $7,410,510$ cases, with 418,294 deaths [3]. This high mortality rate is due to the highly infectious nature of the virus, with an estimated reproductive numbers (R0) in the range of $2.20-2.58$. This important epidemiological estimate means that each patient is able to spread the infection to 2 or 3 healthy people [4].

The length of the virus incubation period (infection to onset of symptoms) is approximately five days [5]. Several studies [6-8] reported median length of viral shedding between 12 and 20 days from onset of symptoms. Previously, cases of prolonged nucleic acid conversion have also been reported, with the longest reported being 60 days [9]. Nucleic acid conversion is defined as the period from the date of symptom onset to the date of the first negative real-time reverse transcription polymerase chain reaction (RT-PCR) test result [10]. It has been hypothesized that prolonged nucleic acid conversion and false negative results of RT-PCR occur in some patients with COVID-19 rather than recurrence of infection [10]. Here, we report four cases of COVID-19 with the possibility of prolonged nucleic acid conversion and false negative results of RT-PCR in Dr. Sardjito Hospital, Indonesia.

\section{Case Presentations}

\section{Case 1}

On March 31, 2020, a 36-year-old male patient complained of coughing up phlegm for one week before admission. He had a history of contact with a positive confirmed case of COVID-19 on March 13, 2020, and swab tests were conducted on March 24 and 25, 2020, with positive results. The physical examination recorded blood pressure of $187 / 94 \mathrm{mmHg}$, pulse of 97 per minute, respiratory rate of 20 per minute, body temperature of $36.3^{\circ} \mathrm{C}$, and oxygen saturation of $98 \%$ breathing room air. Lung auscultation revealed no apparent abnormality. Chest X-rays showed appearance of mild pneumonia in the right lung (Fig. 1). Blood tests showed an increase of neutrophil-lymphocyte ratio (NLR) of 2.03 and C-reactive protein (CRP) of 10mg/L. After admission, the patient received antibiotics and antiviral therapy based on the COVID-19 Prevention and Control guidelines by the Indonesian Ministry of Health, namely azithromycin, hydroxychloroquine, oseltamivir, lopinavir-ritonavir, and umifenovir. SARS-CoV-2 re-testing with nasopharyngeal and oropharyngeal swabs were done with positive results in the $3^{\text {rd }}$ test (April 1), $4^{\text {th }}$ (April 3), and $5^{\text {th }}$ (April 7$)$. In the $6^{\text {th }}$ swab (April 9) the results were negative, but were positive in the $7^{\text {th }}$ swab (April 12). In the $8^{\text {th }}$ swab (April 16) the results returned negative, but were positive in the $9^{\text {th }}$ swab (April 16). Two consecutive negative results were found on the $10^{\text {th }}$ (April 21) and the $11^{\text {th }}$ swab (April 24). The patient was discharged from the hospital on April 25, 2020, following 31 days from the onset of illness (Table 1 ), and was advised to continue self-isolation for 14 days.

\section{Case 2}

On March 15, 2020, a 54-year-old male patient complained of shortness of breath that worsened with activity. The patient began experiencing fever nine days before admission. Three days before admission, he experienced a cough with phlegm. He had a history of contact with a confirmed case of CoVID-19, two weeks before admission, on March 26, 2020. He had a comorbidity of diabetes controlled with routine medication. The physical examination recorded blood pressure of $131 / 72 \mathrm{mmHg}$, pulse of 96 per minute, respiratory rate of 24 per minute, body temperature of $38^{\circ} \mathrm{C}$, and oxygen saturation of $97 \%$ with oxygenation of 2 liters per minute using nasal cannula. Lung auscultation revealed no apparent abnormality. Rapid diagnostic tests using SARS-CoV-2 
antibody were performed and showed non-reactive results. Chest X-rays showed inhomogeneous opacity on bilateral paracardial and lateral aspects, typical with viral pneumonia caused by COVID-19 infection (Fig. 2). We found an increase of NLR and CRP of 2.94 and 107 mg/L, respectively. After admission, the patient received antibiotics and antiviral therapy based on the COVID-19 Prevention and Control guidelines by the Indonesian Ministry of Health, namely azithromycin, hydroxychloroquine, and lopinavir-ritonavir. On the following day, naso/oropharyngeal swabs were done with positive results. On the fifth day of treatment, naso/oropharyngeal swabs were done again and the results were still positive, even though his symptoms were relieved. Positive PCR results were found until the $4^{\text {th }}$ test, but were negative on the $5^{\text {th }}$ test, turned positive again on the $6^{\text {th }}$, and then two consecutive results were found to be negative on the $7^{\text {th }}$ and $8^{\text {th }}$ tests (Table 1). The patient was discharged uneventfully on the May 7, 2020 (after 29 days of treatment), and was advised to continue self-isolation for 14 days.

\section{Case 3}

On April 8, 2020, a 47-year-old man presented with complaints of fever, cough, sore throat, and diarrhea that were experienced from 10 days before admission. Patient has comorbidities of asthma and heart rhythm disorders in the form of ventricular extra systole. He has a history of penicillin allergy. The physical examination recorded blood pressure of $121 / 90 \mathrm{mmHg}$, pulse of 117 per minute, respiratory rate of 20 per minute, body temperature of $36.9^{\circ} \mathrm{C}$, and oxygen saturation of $96 \%$ with room air. Lung auscultation revealed crackles in both lungs. Rapid diagnostic tests using SARS-CoV-2 antibodies were performed and showed reactive results. Chest X-rays showed bilateral pneumonia (Fig. 3). We found an increase of NLR and CRP of 20.90 and $32 \mathrm{mg} / \mathrm{L}$, respectively. Blood culture test was performed and showed negative bacterial growth. After admission, patient received antibiotics and antiviral therapy based on the COVID-19 Prevention and Control guidelines by the Indonesian Ministry of Health, namely azithromycin, hydroxychloroquine, umifenovir and lopinavir-ritonavir. On the 15th day of treatment, he felt chest throbbing and shortness of breath. During treatment, the patient often complained of tightness in the chest and fever that rose suddenly, so we suspected pneumonia. The patient received antibiotic escalation therapy with meropenem and levofloxacin, but his condition did not improve. Naso- and oropharyngeal swab tests were performed 11 times during the course of the treatment, and positive results of SARS-CoV-2 infection were obtained and remained positive, except for the negative results on the $4^{\text {th }}$ and $6^{\text {th }}$ tests. Two consecutive negative results were obtained on the $10^{\text {th }}$ and $11^{\text {th }}$ swabs (Table 1). The patient was discharged uneventfully on May 22, 2020 (after 52 days of treatment) and was advised to continue self-isolation for 14 days.

\section{Case 4}

On April 14, 2020, a 56-year-old woman came to the emergency department with complaints of lethargy that worsened in the last 6 days before admission. Her complaints included with diarrhea daily more than 10 times, without mucus nor blood. Patient also experienced fever for 4 days before admission. The patient went to a private hospital and was hospitalized for 4 days, then was referred to our hospital for further tracking related to her neutropenia condition. She has a history of hyperthyroidism that she had suffered from for the past 1.5 months and has received 100mg twice daily PTU therapy and thiamazole $5 \mathrm{mg}$ once daily. She has a history of penicillin allergy. The physical examination recorded blood pressure of $116 / 53 \mathrm{mmHg}$, pulse of 115 per minute, respiratory rate of 21 per minute, body temperature of $37.5^{\circ} \mathrm{C}$, and oxygen saturation of $99 \%$ with room air. Lung auscultation revealed no apparent abnormality on both lungs. Rapid diagnostic tests using SARS-CoV-2 antibody were performed and showed non-reactive results. Chest X-rays showed bilateral pneumonia (Fig. 4), while routine blood tests revealed pancytopenia. On the ninth day of admission, it was revealed that her husband was known to have flu symptoms and had a rapid diagnostic test for SARS-CoV-2 antibodies with reactive result, and had been examined by nasal and oropharyngeal swab test with positive result. The patient's husband is known to have a history of contact with people traveling from the local COVID-19 transmission area. After admission, our patient received antibiotics and antiviral therapy based on the COVID-19 Prevention and Control guidelines by the Indonesian Ministry of Health, namely azithromycin, hydroxychloroquine, umifenovir and lopinavir-ritonavir. Nasal and oropharyngeal swab tests were performed 14 times during the course of the treatment, and positive results of SARS-CoV-2 infection were obtained and remained positive, except for the negative results on the $2^{\text {nd }}$ and $10^{\text {th }}$ tests (Table 1 ). Two consecutive negative results were obtained on the $13^{\text {th }}$ and $14^{\text {th }}$ swabs (Table 1 ). The patient was discharged uneventfully on June 18,2020 (after 70 days of treatment) and was advised to continue self-isolation for 14 days.

Table 1. RT-PCR findings in COVID-19 patients treated in Dr. Sardjito Hospital, Indonesia.

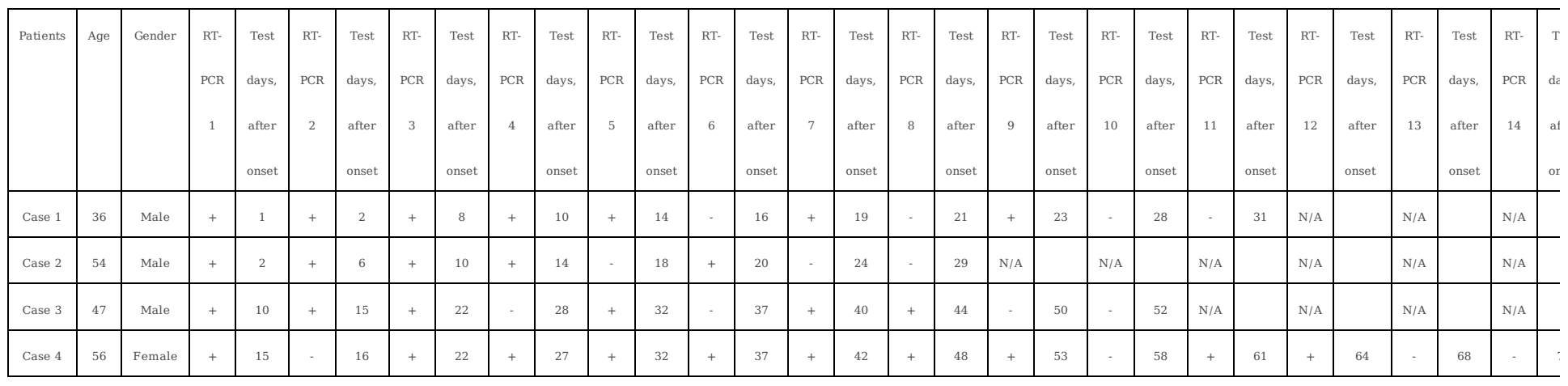




\section{Discussion}

We report the occurrence of prolonged nucleic acid conversion and the possibility of false negative RT-PCR test results of SARS-Cov-2. Prolonged nucleic acid conversion is defined as conversion for more than 24 days from the onset of the typical symptoms of COVID-19 [10]. Interestingly, previous studies have reported that symptomatic and asymptomatic patients have the same viral loads, showing that there is a potential for transmission from patients without or having mild symptoms [11,12]. Our cases recovered from mild symptoms of COVID-19, but experienced an extended duration of viral shedding. Moreover, during the treatment in the hospital, our cases showed negative results in between positive results of RT-PCR. This finding is similar to previous reports $[10,13,14]$ which reported the high false negative rate of RT-PCR for COVID-19 detection. The fluctuating trend of our RT-PCR results in our cases might be due to insufficient viral material in the specimen, laboratory errors during sampling, restrictions on sample transportation [13], or by mutations in the primary and probe target regions in the SARS-CoV-2 genome [15].

Furthermore, until now it is still unclear whether the occurrence of prolonged nucleic acid conversion is related to prolonged infectivity [9]. RT-PCR is indeed a "gold standard" diagnosis of COVID-19 because it detects RNA, but not the active infectious virus. Virus culture study by Bullard et al. [16] reported that virus infectivity decreased significantly when RT-PCR Ct (cycle threshold) values were $>24$. Ct values of RT-PCR tests are inversely related to viral load. For every 1 unit increase in $\mathrm{Ct}$, the odds ratio for infectivity decreases by $32 \%$. Some studies also reported that viral infectivity in patients with symptoms' duration $>8$ days may be low $[16,17]$. Several factors might affect the occurrence of prolonged nucleic acid conversion, including older age, having comorbidities, such as diabetes and hypertension, and impaired immune function [18]. Our cases, except patient \#1, had comorbidities, such as diabetes, hyperthyroid, asthma and arrhythmia.

\section{Conclusion}

Our cases further confirmed the occurrence of prolonged nucleic acid conversion and the possibility of false negative of RT-PCR in patients with COVID-19 instead of recurrence of infection. These findings might have an implication on the management of patients with COVID-19 who have already clinically and radiologically recovered, particularly related to subsequent spreading of the infection in the community.

\section{Abbreviations}

RT-PCR: real-time reverse transcription polymerase chain reaction

Ct: cycle threshold

SARS-CoV-2: severe acute respiratory syndrome coronavirus 2

COVID-19: coronavirus disease 2019

\section{Declarations}

\section{Ethics approval and consent to participate}

The Ethical Committee of the Faculty of Medicine, Public Health and Nursing, Universitas Gadjah Mada/Dr. Sardjito Hospital ruled the study exempt from approval because this study was a case series. The authors attest that full and informed consent was obtained from the patients who had undergone medical treatment in our hospital.

\section{Consent for publication}

Written and informed consent was obtained from the patients for publication of this case report and the associated images.

\section{Availability of data and material}

The datasets used and/or analyzed during the current study are available from the corresponding author on reasonable request

\section{Competing interests}

The authors declare that they have no competing interest.

\section{Funding}

The authors declare that they have no funding source.

\section{Authors' contributions}

IT and G conceived the study. ARF drafted the manuscript, IT RA, and G critically revised the manuscript for important intellectual content. IT and RA facilitated all project-related tasks. All authors have read and approved the manuscript and agreed to be accountable for all aspects of the work in ensuring that questions related to the accuracy or integrity of any part of the work are appropriately investigated and resolved.

\section{Acknowledgment}


We thank the staff and nursing team who were involved in the patient's care.

\section{References}

1. World Health Organization. https://www.who.int/news-room/detail/27-04-2020-who-timeline--covid-19 Accessed on June 14, 2020.

2. Phelan AL, Katz R, Gostin LO, 2020. The novel coronavirus originating in Wuhan, China: challenges for global Health Governance. JAMA 323: 709-710

3. World Health Organization. Coronavirus Disease 2019 (COVID-19) Situation Report - 144. Geneva: WHO; 2020.

4. Al-Balas M, Al-Balas HI, Al-Balas H. Surgery during the COVID-19 pandemic: a comprehensive overview and perioperative care. Am J Surg. 2020.

5. Lauer SA, Grantz KH, Bi Q, Jones FK, Zheng Q, Meredith HR, Azman AS, Reich NG, Lessler J. The incubation period of coronavirus disease 2019 (COVID-

19) from publicly reported confirmed cases: estimation and application. Ann Intern Med. 2020;172:577-82.

6. Qian GQ, Chen XQ, Lv DF, Ma AH, Wang LP, Yang NB, Chen XM. Duration of SARS-CoV-2 viral shedding during COVID-19 infection. Infect Dis (Lond) 0: 12.

7. Xu K, Chen Y, Yuan J, Yi P, Ding C, Wu W, Li Y, Ni Q, Zou R, Li X, Xu M. Factors associated with prolonged viral RNA shedding in patients with COVID-19. Clin Infect Dis. 2020.

8. Zhou F, Yu T, Du R, Fan G, Liu Y, Liu Z, Xiang J, Wang Y, Song B, Gu X, Guan L. Clinical course and risk factors for mortality of adult inpatients with CoVID19 in Wuhan, China: a retrospective cohort study. The Lancet. 2020.

9. Li J, Zhang L, Liu B, Song D. Case report: viral Shedding for 60 Days in a woman with COVID-19. Am J Trop Med Hyg. 2020;102:1210-3.

10. Xiao AT, Tong YX, Zhang S. False-negative of RT-PCR and prolonged nucleic acid conversion in COVID-19: rather than recurrence. J Med Virol. 2020.

11. Zou L, Ruan F, Huang M, Liang L, Huang H, Hong Z, Yu J, Kang M, Song Y, Xia J, Guo Q. SARS-CoV-2 viral load in upper respiratory specimens of infected patients. N Engl J Med. 2020;382:1177-9.

12. Rothe C, Schunk M, Sothmann P, Bretzel G, Froeschl G, Wallrauch C, Zimmer T, Thiel V, Janke C, Guggemos W, Seilmaier M. Transmission of 2019-nCoV infection from an asymptomatic contact in Germany. N Engl J Med. 2020;382:970-1.

13. Li Y, Yao L, Li J, Chen L, Song Y, Cai Z, Yang C. Stability issues of RT-PCR testing of SARS-CoV-2 for hospitalized patients clinically diagnosed with COVID19. J Med Virol. 2020

14. Lan L, Xu D, Ye G, Xia C, Wang S, Li Y, Xu H. Positive RT-PCR test results in patients recovered from COVID-19. JAMA. 2020;323:1502-3.

15. Tahamtan A, Ardebili A. Real-time RT-PCR in COVID-19 detection: issues affecting the results. Expert Rev Mol Diagn, DOI: 10.1080/14737159.2020.1757437

16. Bullard J, Dust K, Funk D, Strong JE, Alexander D, Garnett L, Boodman C, Bello A, Hedley A, Schiffman Z, Doan K. Predicting infectious SARS-CoV-2 from diagnostic samples. Clin Infect Dis. 2020

17. Hu X, Xing Y, Jia J, Ni W, Liang J, Zhao D, Song X, Gao R, Jiang F. Factors associated with negative conversion of viral RNA in patients hospitalized with COVID-19. Sci Total Environ. 2020:138812.

18. Xiao AT, Tong YX, Zhang S. Profile of RT-PCR for SARS-CoV-2: a preliminary study from 56 COVID-19 patients. Clin Infect Dis

\section{Figures}

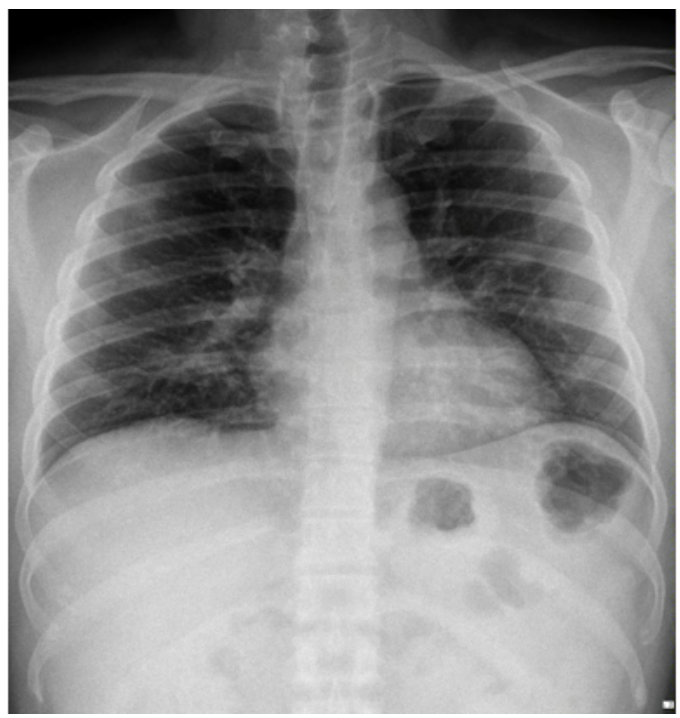

\section{Figure 1}

Figure 1. Chest x-ray indicated mild pneumonia in the right lung. 


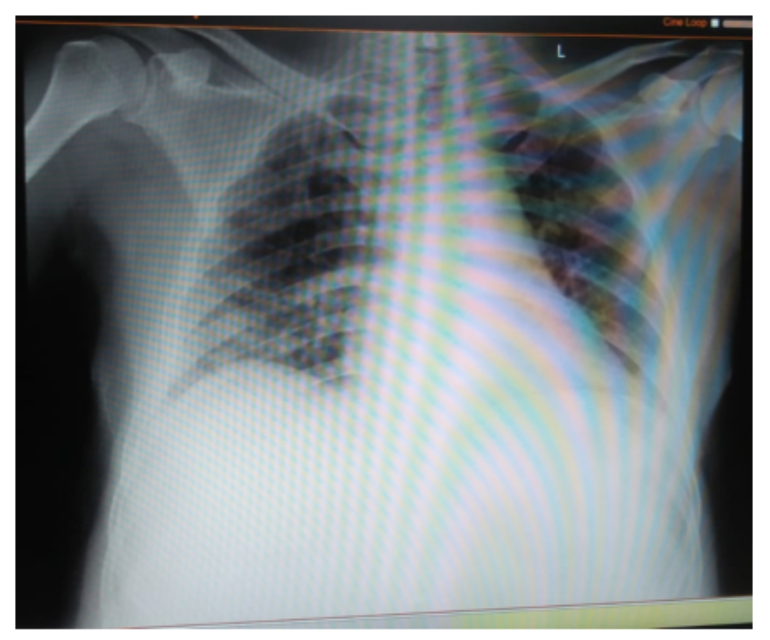

\section{Figure 2}

Figure 2. Chest x-ray revealed inhomogeneous opacity on bilateral paracardial and lateral aspects.

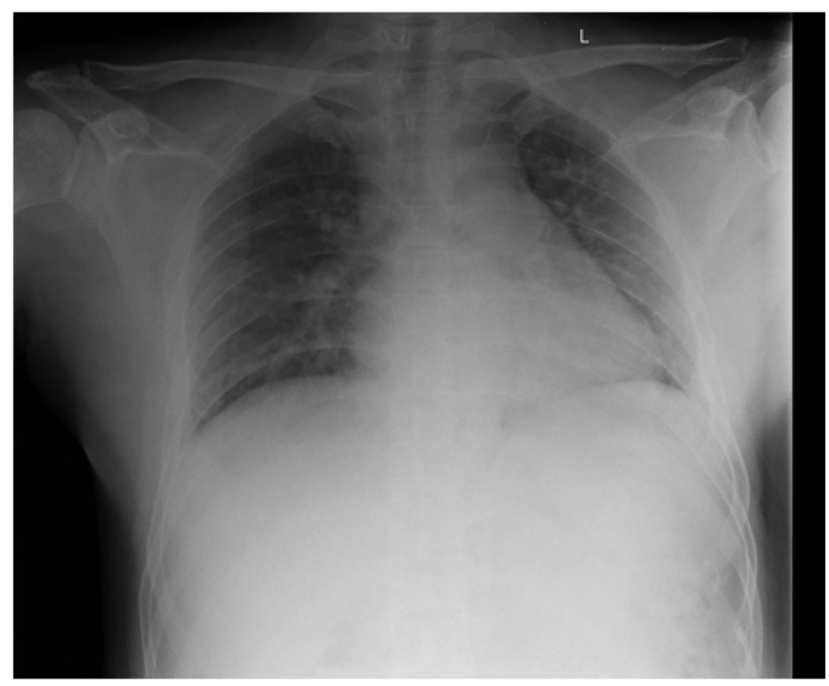

\section{Figure 3}

Figure 3. Chest x-ray presented bilateral pneumonia.

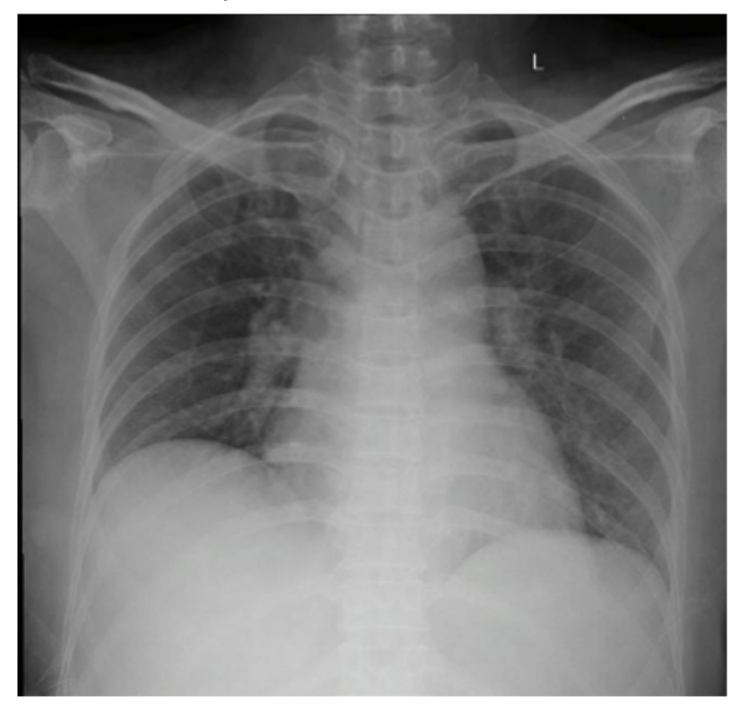

Figure 4 
Figure 4. Chest x-ray showed bilateral pneumonia.

Page 7/7 